\title{
Erratum: Calculation of the wake due to radiation and space charge forces in relativistic beams \\ [Phys. Rev. Accel. Beams 24, 020701 (2021)]
}

Gennady Stupakov@ and Jingyi Tang

(Q) (Received 27 August 2021; published 14 September 2021)

DOI: 10.1103/PhysRevAccelBeams.24.099901

The expression for function $F$ in Eq. (18) should read

$$
\begin{aligned}
F= & \epsilon\left(\alpha^{2}+1\right) D^{3}\left(h^{2} \sigma_{z 0}^{2}+\sigma_{\eta}^{2}\right)+2 \epsilon \alpha \beta_{\mathrm{f}} D^{2} D^{\prime}\left(h^{2} \sigma_{z 0}^{2}+\sigma_{\eta}^{2}\right) \\
& +\epsilon \beta_{\mathrm{f}} D\left[h \sigma_{z 0}^{2}\left(\alpha+\beta_{\mathrm{f}} D^{\prime 2} h+\alpha h R_{56}\right)+\sigma_{\eta}^{2}\left(\beta_{\mathrm{f}} D^{\prime 2}+\alpha R_{56}\right)+\epsilon\right]+\epsilon \beta_{\mathrm{f}}^{2} D^{\prime}\left[h \sigma_{z 0}^{2}\left(h R_{56}+1\right)+R_{56} \sigma_{\eta}^{2}\right],
\end{aligned}
$$

and the second equation in Eq. (B8) should be

$$
2 e a+\frac{b}{R}=-a^{\prime}
$$

The function $c\left(s^{\prime}\right)$ in Eq. (31) should be replaced by $d\left(s^{\prime}\right)$. These errors do not change the results of the paper.

\section{ACKNOWLEDGMENTS}

We would like to thank Cheng-Ying Tsai for finding these errors in our paper.

Published by the American Physical Society under the terms of the Creative Commons Attribution 4.0 International license. Further distribution of this work must maintain attribution to the author(s) and the published articles title, journal citation, and DOI. 